\title{
Gender-specific lethality due to carbon monoxide poisoning in Morocco
}

\author{
Mohammed Chahboune ${ }^{1,2}$, Abderrazzak Khadmaoui ${ }^{2}$, Abdelmajid Soulaymani², Abdelrhani Mokhtari $^{2}$, François Xavier \\ Nshimiyimana ${ }^{1}$ and Rachida Soulaymani-Bencheikh ${ }^{3}$
}

${ }^{1}$ Faculty of Environmental Studies, University of Lay Adventists of Kigali, Kigali, Rwanda

${ }^{2}$ Biology and Health Laboratory, Ibn Tofail University, Faculty of Science, Kenitra, Morocco

${ }^{3}$ Moroccan Anti-poison and Pharmaco-vigilance Center, Rabat, Morocco

\begin{abstract}
The objective of this study is to assess trends in death cases caused by carbon monoxide poisoning and to determine the possible reasons for a risk predisposition for a given sex in the event of a possible trend. In doing so, professionals working in the field of prevention take into account in control programs.

Methods: Study of the regional and national evolution of sex-specific lethalities due to carbon monoxide poisoning based on deaths reported by the Anti-poison Center and Pharmacovigilance (CAPM) in the 16 regions for the period 1999-2013.

Results: The chronological evolution of case-specific mortality rates on the whole shows an increasing trend for both sexes, which is in perfect proportion with the growth of deaths reported because of $\mathrm{CO}$ in the different regions. However, the values for the male, whose average for the period studied is $1.106 \%$, are larger than those for females, whose average is only $0.618 \%$. This more masculine tendency of lethalities cannot obviously be attributed to sex, nor to the particularities of deadly human CO exposure since all deaths are accidental and not related to socio-professional characteristics.

Conclusion: The fatal risk in case of $\mathrm{CO}$ intoxication seems to favor a rather masculine superiority. This difference in lethality is simply explained by differences in the frequencies of poisoning and their fatal evolutions. Indeed, the quotient would be more masculine since the deaths due to the CO are practically similar for both sexes, whereas the frequency of the intoxications is more feminine.
\end{abstract}

Keywords: Intoxication, Sex-specific lethality, carbon monoxide, Morocco

\section{Introduction}

The number of carbon monoxide $(\mathrm{CO})$ poisoning cases and the resulting deaths highlight the importance of this health problem in Morocco. In fact, the epidemiological surveillance carried out by the CAPM and the prevention strategies resulting from it do not seem to reduce the occurrence of poisonings and deaths, which are nevertheless preventable [1-5].

The historical review of the death declarations received by the CAPM, from its creation in 1980 until 2013, shows, on the one hand, the unintentional aspect of the occurrence of CO poisoning because, since 1992, the date of the first notifications, out of 211 death cases, only one case in 1995 was suicidal. On the other hand,
$88 \%$ of deaths were reported from the year 2000 (185 cases) because the Toxicovigilance and Toxicological Information systems have matured much more over the years $[4,5]$.

This study is a comparative evaluation of the specific lethalities to the two sexes, from the cases of poisoning and death cases due to poisoning by $\mathrm{CO}$ that reached the CAPM during a period of 15 years from 1999 to 2013, to through the annual and regional monitoring of variations in these indicators. This is done in the hope of contributing to better understanding the characteristics of $\mathrm{CO}$ poisoning in Morocco for better programming of the fight against this pathology.

\section{Data and Methods}

\footnotetext{
*Corresponding author: chahboune.mohamed@uit.ac.ma
} 
The spatio-temporal analysis of male-specific lethalities (MSL) and female-specific lethalities (FLS) resulting from $\mathrm{CO}$ poisoning and as a means of measuring health, is based on the filtration of cases of death occurring between 1999 and 2013 listed in the CAPM's exhaustive database formed from its information systems: Toxicovigilance and Toxicological Information.

The analysis and the use of the data were conducted by Epi-Info and Excel software and for the cartographic visualization of the regional distribution of the indicators were examined, and the Geographic Information System was used.

Male-specific and female-specific lethalities are determined in terms of the percentages that express the number of death cases caused by intoxication, for one sex, in comparison to the number of new intoxicated cases of the same sex, during a year time.

\section{Results}

The incrimination of $\mathrm{CO}$ in poisoning and in death cases in Morocco has already been demonstrated by reports from the CAPM and scientific studies in Morocco [1-8]. These research studies have shown the connection of these poisonings with the climate and recklessness in the use of gas, wood or charcoal heating systems.

The fatal development concerned 185 cases among the 20,683 cases of $\mathrm{CO}$ poisoning that occurred during the period 1999-2013 according to the records of the CAPM, i.e. $14.93 \%$ of deaths linked to all poisonings notified during the same period in Morocco. This represents an average of 13 deaths per year. $77.84 \%$ of the cases (144 cases) arrived by mail, $16.76 \%$ (31 cases) by the toxicological information system and $5.4 \%$ (10 cases) by the press and studies.

Also, the results showed that the occurrence of deaths is totally accidental, but yet seasonal. In fact, $52.76 \%$ of cases are observed in winter and 29.45 in Autumn. This is confirmed by the monthly distribution which shows a maximum of $21.08 \%$ of cases recorded during the month of December, followed by the months of February with $19.46 \%$ and January with $17.84 \%$.

Moreover, the distribution of deaths according to the environment and the place of poisoning demonstrates that they occur for the mainly in urban areas, i.e. $78.74 \%$ of cases, and at home in $95.51 \%$ of cases.

The male/female ratio shows a sex ratio for deaths of 0.91 , slightly in favor of the female sex. With regard to the age of the deceased, adults constitute the majority with $69.36 \%$ of cases.
To analyze the annual change in male-specific and female-specific lethalities from $\mathrm{CO}$ poisoning at the regional level, the period 1999-2013 is subdivided into three-year intervals. Thus, Tables 1 and 2 which illustrate this distribution show, for both sexes, that specific lethalities are not recorded continuously over time because of the annual irregularity in the occurrence of death cases in all regions. This eventually attests to the accidental aspect of poisoning and its fatal course.

In fact, over the 15 years studied, the region of Meknès-Tafilalt was concerned by lethalities for 9 years, Marrakech-Tansift-Al Haouz for 8 years, the Oriental for 7 years, Fès-Boulmane, Rabat-Salé-Zemmour -Zaer and Tanger-Tétouan for 6 years, Doukkala-Abda, SoussMassa-Daraa and Taza-Al Hoceima-Taounate for 5 years, Gharb-Chrarda- Beni Hssen and Grand Casablanca for 4 years, Tadla-Azilal for 3 years and Doukkala-Abda for only 2 years. In the regions of southern Morocco (Guelmim-Es Semara, LaayouneBoujdour-Sakia El Hamra and Oued ed Dahab-Lag Will), the specific lethality for both sexes was always zero throughout the period examined.

Table 1. Regional distribution of male-specific lethalities from poisoning by carbon monoxide in Morocco during the period 1999-2013

\begin{tabular}{|l|l|l|l|l|l|}
\hline Region & $\begin{array}{l}\text { MSL } \\
\mathbf{9 9 - 0 1}\end{array}$ & $\begin{array}{l}\text { MSL } \\
\mathbf{0 2 - 0 4}\end{array}$ & $\begin{array}{l}\text { MSL } \\
\mathbf{0 5 - 0 7}\end{array}$ & $\begin{array}{l}\text { MSL } \\
\mathbf{0 8 - 1 0}\end{array}$ & $\begin{array}{l}\text { MSL } \\
\mathbf{1 1 - 1 3}\end{array}$ \\
\hline Chaouia-Ouardigha & 0 & 5 & 1,923 & 0 & 0 \\
\hline Doukkala-Abda & 2,174 & 1,37 & 0 & 7,692 & 3,333 \\
\hline Fes-Boulmane & 0 & 0 & 0 & 1,554 & 1,546 \\
\hline $\begin{array}{l}\text { Gharb-Chrarda- Beni } \\
\text { Hssen }\end{array}$ & 0 & 10,81 & 0 & 4,545 & 1,136 \\
\hline Grand Casablanca & 0 & 0 & 0 & 0 & 1,739 \\
\hline Guelmim-Es Semara & 0 & 0 & 0 & 0 & 0 \\
\hline L'Oriental & 0 & 0 & 1,042 & 1,449 & 3,279 \\
\hline $\begin{array}{l}\text { Laayoune-Boujdour- } \\
\text { Sakia El Hamra }\end{array}$ & 0 & 0 & 0 & 0 & 0 \\
\hline $\begin{array}{l}\text { Marrakech-Tansift- } \\
\text { Al Haouz }\end{array}$ & 0 & 0 & 2,804 & 1,389 & 0 \\
\hline Meknes-Tafilalt & 0 & 1,418 & 1,681 & 0,315 & 2,857 \\
\hline $\begin{array}{l}\text { Oued ed Dahab- } \\
\text { Laguira }\end{array}$ & 0 & 0 & 0 & 0 & 0 \\
\hline $\begin{array}{l}\text { Rabat-Salé- } \\
\text { Zemmour-Zaer }\end{array}$ & 0 & 0 & 4,348 & 4 & 3,175 \\
\hline Souss-Massa-Daraa & 0 & 0 & 1,818 & 1,639 & 5,455 \\
\hline Tadla-Azilal & 0 & 0 & 0 & 0 & 1,111 \\
\hline Tanger-Tétouan & 0 & 0 & 0 & 1,423 & 0,563 \\
\hline $\begin{array}{l}\text { Taza-Al Hoceima- } \\
\text { Taounate }\end{array}$ & 0 & 0 & 0 & 5,714 & 5,747 \\
\hline National average & 0,171 & 0,764 & 1,263 & 1,325 & 2,023 \\
\hline
\end{tabular}


Table 2. Regional distribution of female-specific lethalities from poisoning by carbon monoxide in Morocco during the period 1999-2013

\begin{tabular}{|l|l|l|l|l|l|}
\hline Region & $\begin{array}{l}\text { FSL } \\
\mathbf{9 9 1}\end{array}$ & $\begin{array}{l}\text { FSL } \\
\mathbf{0 2 - 0 4}\end{array}$ & $\begin{array}{l}\text { FSL } \\
\mathbf{0 5 - 0 7}\end{array}$ & $\begin{array}{l}\text { FSL } \\
\mathbf{0 8 - 1 0}\end{array}$ & $\begin{array}{l}\text { FSL } \\
\mathbf{1 1 - 1 3}\end{array}$ \\
\hline Chaouia-Ouardigha & 0 & 0 & 0 & 0 & 0 \\
\hline Doukkala-Abda & 1,124 & 1,031 & 0 & 0 & 0 \\
\hline Fes-Boulmane & 0 & 8,696 & 0 & 1,671 & 0,594 \\
\hline $\begin{array}{l}\text { Gharb-Chrarda- Beni } \\
\text { Hssen }\end{array}$ & 0 & 4,688 & 0 & 0 & 0,515 \\
\hline Grand Casablanca & 0,495 & 1,075 & 0 & 0 & 1,13 \\
\hline Guelmim-Es Semara & 0 & 0 & 0 & 0 & 0 \\
\hline L'Oriental & 0 & 0 & 0 & 2,5 & 1,351 \\
\hline $\begin{array}{l}\text { Laayoune-Boujdour- } \\
\text { Sakia El Hamra }\end{array}$ & 0 & 0 & 0 & 0 & 0 \\
\hline $\begin{array}{l}\text { Marrakech-Tansift- } \\
\text { Al Haouz }\end{array}$ & 0,633 & 0,4 & 1,183 & 0,717 & 0 \\
\hline Meknes-Tafilalt & 0 & 0,897 & 0,388 & 0,464 & 0,723 \\
\hline $\begin{array}{l}\text { Oued ed Dahab- } \\
\text { Laguira }\end{array}$ & 0 & 0 & 0 & 0 & 0 \\
\hline $\begin{array}{l}\text { Rabat-Salé- } \\
\text { Zemmour-Zaer }\end{array}$ & 0 & 0 & 1,695 & 0 & 1,761 \\
\hline Souss-Massa-Daraa & 0 & 0 & 2,778 & 0 & 0,82 \\
\hline Tadla-Azilal & 0 & 0,311 & 0,337 & 0 & 0 \\
\hline Tanger-Tétouan & 0 & 1,07 & 0 & 0,35 & 1,056 \\
\hline $\begin{array}{l}\text { Taza-Al Hoceima- } \\
\text { Taounate }\end{array}$ & 0 & 0 & 0 & 8,929 & 0,641 \\
\hline National average & 0,207 & 0,837 & 0,451 & 0,92 & 0,767 \\
\hline
\end{tabular}

Moreover, the annual change in male-specific lethalities and female-specific lethalities during the same period nationwide represented by table 3 and the graphic representation of figure 1 , show, on the one hand, that at 1 except for the years 2001 and 2002, which did not record male deaths for the first, and female deaths for the second. All the other years were marked by variable rates of fatalities. On the other hand, 2013 recorded the highest value of specific lethality for males $(2.442 \%)$, while for females the highest rate was observed in 2003 $(1.562 \%)$.

Table 3. Annual distribution of fatalities specific to males and females at the national level during the period 1999-2013

\begin{tabular}{|l|l|l|l|l|l|l|}
\hline Year & $\begin{array}{c}\text { Male } \\
\text { intoxicated } \\
\text { cases }\end{array}$ & $\begin{array}{c}\text { Female } \\
\text { intoxicated } \\
\text { cases }\end{array}$ & $\begin{array}{c}\text { Number } \\
\text { of } \\
\text { deaths } \\
\text { male }\end{array}$ & $\begin{array}{c}\text { Number } \\
\text { of } \\
\text { deaths } \\
\text { female }\end{array}$ & $\begin{array}{c}\text { MSL } \\
\text { in \% }\end{array}$ & $\begin{array}{c}\text { FSL } \\
\text { in \% }\end{array}$ \\
\hline 1999 & 204 & 502 & 0 & 0 & 0 & 0 \\
\hline 2000 & 210 & 491 & 1 & 2 & 0,476 & 0,407 \\
\hline 2001 & 170 & 459 & 0 & 1 & 0 & 0,218 \\
\hline 2002 & 219 & 453 & 1 & 0 & 0,457 & 0 \\
\hline
\end{tabular}

\begin{tabular}{|l|l|l|l|l|l|l|}
\hline 2003 & 325 & 576 & 3 & 9 & 0,9237 & 1,563 \\
\hline 2004 & 372 & 644 & 3 & 5 & 0,807 & 0,7767 \\
\hline 2005 & 386 & 732 & 7 & 2 & 1,814 & 0,2737 \\
\hline 2006 & 464 & 864 & 7 & 7 & 1,509 & 0,8102 \\
\hline 2007 & 417 & 845 & 2 & 2 & 0,480 & 0,237 \\
\hline 2008 & 461 & 1052 & 6 & 8 & 1,302 & 0,761 \\
\hline 2009 & 558 & 1109 & 5 & 11 & 0,896 & 0,992 \\
\hline 2010 & 566 & 1208 & 10 & 12 & 1,767 & 0,993 \\
\hline 2011 & 549 & 1310 & 12 & 8 & 2,186 & 0,611 \\
\hline 2012 & 848 & 1863 & 13 & 17 & 1,533 & 0,913 \\
\hline 2013 & 778 & 1522 & 19 & 11 & 2,442 & 0,723 \\
\hline
\end{tabular}

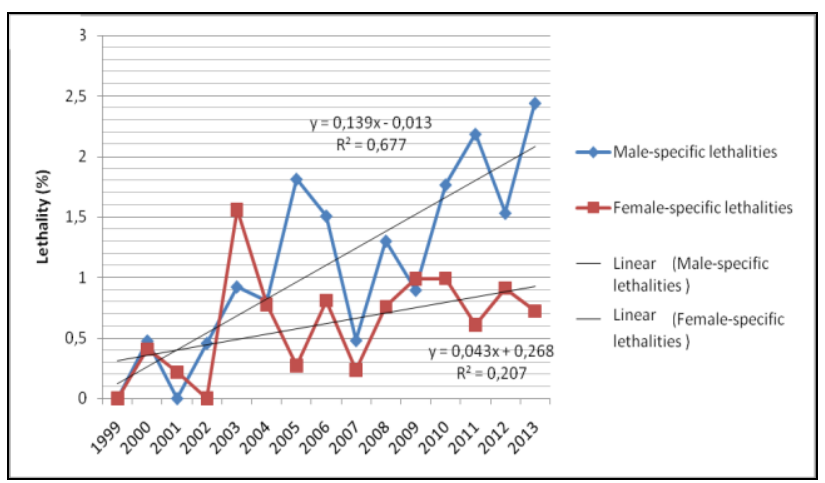

Figure 1. Annual change in sex-specific lethality due to carbon monoxide poisoning at the national level during the period 1999-2013

\section{Discussion}

The magnitude of the recorded mean values of male-specific and female-specific lethalities for the period 1999-2013, illustrated by Figure 2 and geographically assessed by Figure 3, generally shows that higher rates are observed for the male sex.

In fact, the results obtained in the region of Taza-Al Hoceima-Taounate because of the underestimates of cases are recorded in 2008, 2010, 2011 and 2012, maximum average rates of around $3 \%$ are recorded in the regions of Doukkala-Abda, Rabat-Salé-ZemmourZaer and Gharb-Chrarda- Beni Hssen, average values between 1 and $2 \%$ were in the regions of Souss-MassaDaraa, Meknes-Tafilalt and the Oriental whereas the other regions recorded average rates below $1 \%$.

However, for the female sex, a maximum not exceeding $1.113 \%$ is observed in the region of Gharb-ChrardaBeni Hssen. 


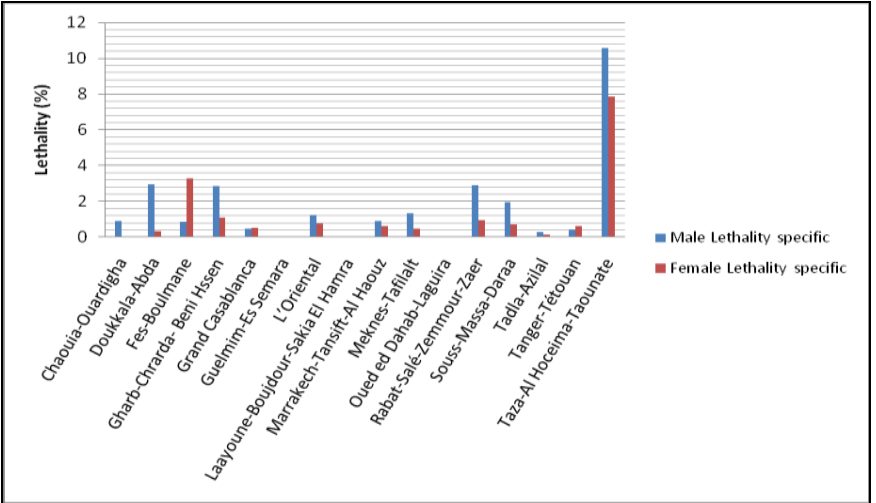

Figure 2. Evolution of regional averages for the period 19992013 of sex-specific lethalities due to carbon monoxide poisoning

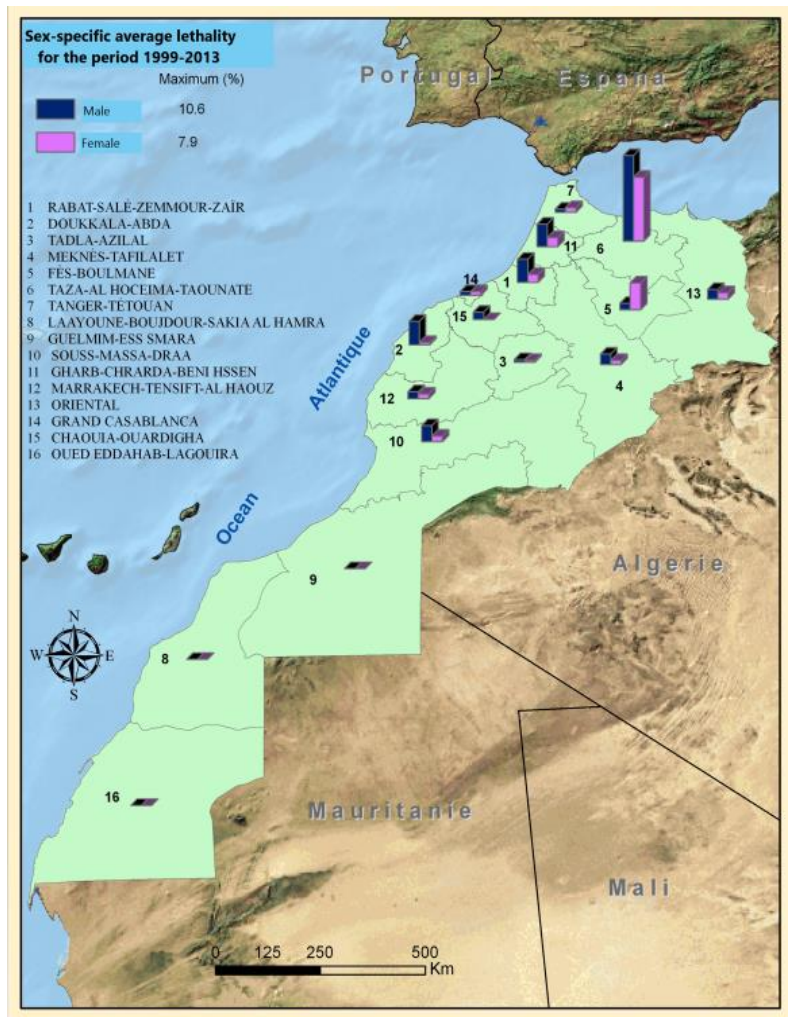

Figure 3. Cartographic representation of the averages for the period 1999-2013 of sex-specific lethalities due to carbon monoxide poisoning

The observation is almost the same nationwide because with the exception of the year 1999, where the specific lethalities for both sexes were zero, and of the years 2001, 2003 and 2009 which recorded higher FSL, the MSL was still higher during the other 11 years as shown in Figure 1 and Table 3.

The evolution over this period and space of sex-specific lethalities in Morocco therefore shows that the risk of death from $\mathrm{CO}$ poisoning targets both sexes [5]. However, rates for males appear to be higher at both regionally and nationally.

This male severity of CO poisoning obviously cannot be related to sex because men and women have identical distribution of health condition and welfare. Moreover, there are no sociological or professional specificities that could explain this disparity. However, the review of the evolution of the frequencies of poisoning and deaths due to $\mathrm{CO}$, illustrated by figures 4 and 5 , shows a female superiority of the number of intoxicated people during the entire period examined with a sex ratio of 0.48 [4] whereas the deaths show generally a similarity in number between the two sexes with a sex ratio for the period studied of 0.94 [5]. Put differently, the specific lethality which is the quotient between the two values will be more serious for the male sex.

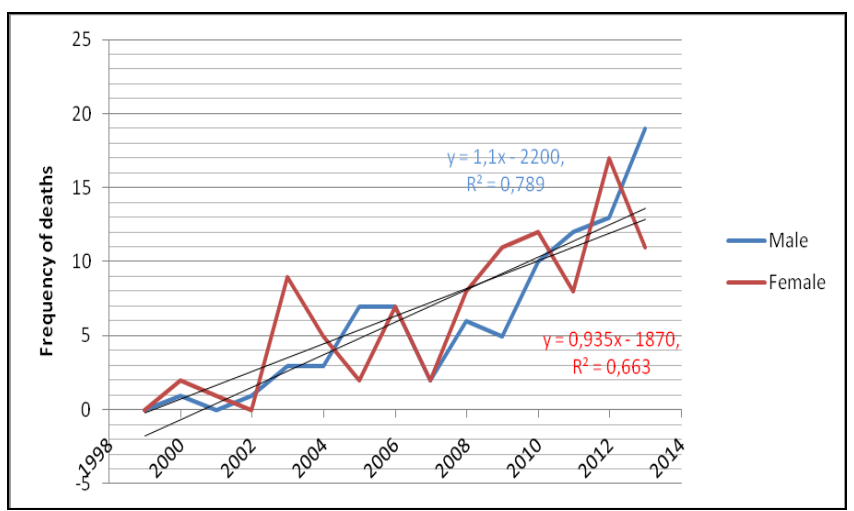

Figure 4. The Evolution of death frequencies due to $\mathrm{CO}$ poisoning

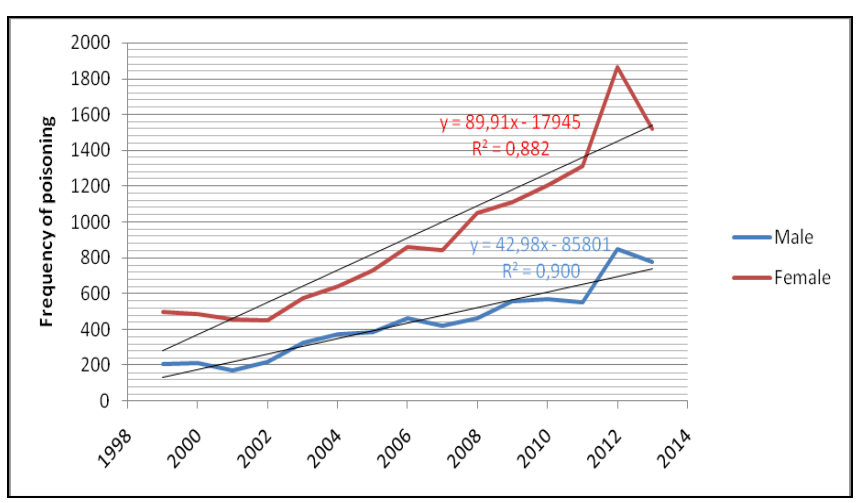

Figure 5. Evolution of $\mathrm{CO}$ poisoning frequencies

However, these results above do not suggest in any way possible that this is a universal phenomenon unless one verifies the gender-specific lethality trends of $\mathrm{CO}$ poisoning in other countries. On the contrary, the accidental nature of death which can target either sex at random cannot be overlooked.

\section{Conclusion}

The fatal effects increasing over time of carbon monoxide poisoning induce a serious public health problem in Morocco. This increase in death cases which is entirely due to accidental occurrences shows overall plausibility in number between the male and female sex compared to the frequency of poisoning which was 
always more important in time and space for the female sex. This generates lethalities specific to the male sex which are generally greater at both regional and national levels.

The seriousness of carbon monoxide, regardless of being preventable, promotes more reactivity of the CAPM through its awareness campaigns to defeat this quotient which spares no age and no gender.

\section{References}

1. Aghandous, N Rhalem, I Semllali, S Belarabi, A Soulaymani, L Ouammi, R Soulaymani Benchikh. Profil épidémiologiques des intoxications par le monoxyde de carbone au Maroc (1991-2007). Toxicologie Maroc- $\mathrm{N}^{\circ} 3-0$ ctobre (2009)

2. R Aghandous, H Chaoui, N Rhalem, I Semllali, M Badri, A Soulaymani, L Ouammi, R Soulaymani Benchikh. Poisoning by carbon monoxide in Morocco from 1991 to 2008. J Pak Med Assoc. Vol. 62, No. 4, April (2012)

3. A Khattabi, N Rhalem, R El Oufir, L Ouammi, A Soulaymani, R Soulaymani Bencheikh. Epidémiologie des décès par empoisonnement au Maroc: Données du Centre Anti Poison et de Pharmacovigilance du Maroc (1992-2009). Toxicologie Maroc. N 13. 2ème trimestre (2012)

4. Chahboune M, Soulaymani A, Batchi M, Aghandous R, Soulaymani-Bencheikh R, Mokhtari A. Evolution régionale des incidences des intoxications au monoxyde de carbone au Maroc. International Journal of Innovation and Applied Studies ISSN 20289324 Vol. 17 No. 3 Aug., pp. 749-756 (2016)

5. Chahboune M, Soulaymani A, SoulaymaniBencheikh R, Aghandous R, Mokhtari A. Mortalité due au monoxyde de carbone dans les régions du Maroc à forte incidence de l'intoxication. European Journal of Scientific Research. ISSN 1450-216X / 1450-202X Vol. 147 No 2 October, 2017, pp. 118-124 (2017)

6. B El Bouhali, N Nekkal, A Bidi, S Belamalem, I Nasri, A Mokhtari, M Eddouks, A Khadmaoui, A Soulaymani. Les intoxications par les produits gazeux au niveau de la province d'Errachidia, region de Meknès Tafilalt, Maroc. International Journal of Innovation and Scientific Research. Vol 11. $\mathrm{N}^{\circ}$ 1. Oct, pp. 41-47 (2014)

7. R Aghandous, N Rhalem, H Chaoui, L Ouammi, A Soulaymani, A Mokhtari, R Soulaymani-Bencheikh. Perception Survey of Carbon Monoxide Risk in RabatSalé-Zemmour-Zaër. Populations Journal of Life
Sciences, ISSN 1934-7391, USA January 2014, Vol. 8, No. 1, pp. 89-94 (2014)

8. N Attazagharti. Epidémiologie des intoxications au Maroc (1992-2007). Evaluation des facteurs de risque influençant l'évolution des patients intoxiqués. Thèse soutenue en (2009) 